\title{
EL ÁNIMA SOLA: ENRIQUE BUENAVENTURA ADAPTA A TOMÁS CARRASQUILLA
}

\author{
Carolina Ramos Fernández
}

Universidad de Sevilla

\begin{abstract}
The Colombian playwright Enrique Buenaventura adapted for the scene the story of qualified Tomás Carrasquilla "The alone soul".

It is not the first time that the first one adapts to the second one so his pieces: In the God's righthand side father, The Guariconga (inspired by the work Palonegro); San Antonito also they inspired also by the work of the novelist, taking it as a point of item for his theatrical theory.

In all the cases, Enrique Buenaventura searches, in Tomás Carrasquilla's work, the popular voice, the autochthonous speech, the known topic and the direct communication with the spectators and spectators of his epoch. Ingredients with which it re-elaborates the popular history opening new points of view, renewing prominent figures and introducing new characters without interferences.
\end{abstract}

\section{LA BUSCONA}

Una historia no es nunca de una sola manera

(El ánima sola, p. 352)

La relación del dramaturgo colombiano Enrique Buenaventura con la producción literaria del escritor Tomás Carrasquilla fue prolífica. No porque trabajaran juntos, sino porque el primero tomó, como fuente de inspiración, las narraciones del segundo; llegando a realizar cuatro versiones teatrales de algunos de sus cuentos con el Teatro Experimental de Cali ${ }^{1}$.

Las piezas referidas son: En la diestra de Dios padre, La Guariconga (inspirado en la obra titulada Palonegro); San Antoñito y El ánima sola, eje del presente estudio.

En todos los casos, Enrique Buenaventura busca, en el trabajo de Tomás Carrasquilla, la voz popular, el habla autóctona, el tema conocido y la comunicación directa con los espectadores y espectadoras de su época.

\footnotetext{
${ }^{1}$ Hubiese sido imposible una colaboración contemporánea pues Tomás de Carrasquilla vivió entre los años 1850 y 1940, mientras el dramaturgo lo hizo entre los años 1925 y 2003. Es decir, el primero murió cuando el segundo tenía sólo 15 años.
} 
En este sentido, ambos encuentran en los mitos y las leyendas de su país, una fuente temática inagotable desde la que poder realizar diferentes propuestas literarias ${ }^{2}$.

Así, en lugar de acudir a la mitología grecolatina, más propia de las literaturas europeas, tanto Carrasquilla como Buenaventura revisan la tradición oral de su país para realizar variantes contemporáneas de las mismas. Y ahí es donde se encuentran con el mito de "El Ánima Sola", una historia entre la superstición y la religión que firma el dramaturgo, en la ciudad de Cali, el día 24 de julio del año 1988.

"El Ánima sola" parte de una referencia bíblica que se ha ido modificando con el paso de los años y atendiendo a las múltiples referencias culturales, propias de cada zona. Así, en la zona occidental de Colombia, de donde procede el novelista colombiano, los campesinos y las campesinas transforman a esta mujer en una especie de amuleto de la suerte. Y son múltiples las referencias que existen a ella como talismán para encontrar tesoros ocultos, objetos perdidos o de la buena suerte.

La historia bíblica sin embargo, es un tanto distinta. Así, el texto religioso se refiere al hecho de que en Jerusalén había un grupo de mujeres que tenía como oficio dar de beber a quienes recibían, como castigo, la crucifixión. El Viernes Santo le tocaba el turno a Celestina Abnegada, quien decidió dar de beber a Dimas y a Gesta, pero no a Jesús. Un desaire que le valió una condena: sufrir sed y calor constantes en las llamas del purgatorio.

Con el paso de los años, de la narración original sólo queda la referencia femenina, pues quienes la adoran en Colombia le asignan el papel protectora del hogar y dedican dos días a su devoción: por un lado, el 2 de noviembre (Día de Ánimas) y, por otro, el Viernes Santo, cuando se le reza después del primer canto del gallo.

Hoy día, en ese mismo país, todavía se le considera un alma purificada que posee la capacidad de obrar milagros y que protege a las personas que más lo necesitan en momentos difíciles de su vida.

Sin embargo, en las dos obras que aquí se estudian, la figura del Ánima sola aparece como alma en pena que quiere venganza para poder descansar y vivir su

2 Como señala Alberto Castilla, Enrique Buenaventura tenía especial predilección por “(...) convertir en materia dramática, con un sello de originalidad, otros temas y textos literarios de carácter no teatral" (p. 65) Un comportamiento que le llevó a adaptar no sólo las obras aquí destacadas, sino piezas de otros autores. Uno de los más destacados su versión de Tirano Banderas, el original de Ramón María del Valle-Inclán. Alberto CASTILLA "Tirano Banderas, Versión Teatral de Buenaventura”, in: Latin American Theatre Review, 10.2, 1977, 65-71. 
penitencia de forma tranquila. Es decir, ambos centran su atención en posibilitar una final a la penitencia.

Así pues, Tomás Carrasquilla elabora un cuento en el que aborda la tragedia de una familia que se agota como consecuencia de una malintencionada opinión. Una intención que se resume en una sola palabra, suficiente para derrumbar a una persona y provocar un efecto dominó en todos y en todo cuanto le rodea.

De esta manera, el novelista arma la historia de Timbre de Gloria, un hombre joven en el que está depositada la semilla de una estirpe de héroes y conquistadores, que echa su vida a perder influido porque, en un momento y ante la toma de una decisión tan importante como la de contraer matrimonio con una mujer a la que ama, su maestro predilecto, Reinaldo, le muestre sus dudas ante esta decisión. Esta actitud hace que Timbre de Gloria anule su compromiso, enloquezca por no saber el significado exacto de las palabras de su maestro -quien desaparece, además, de su lado para provocarle más angustia y no ofrecerle la respuesta que solicita- y acabe suicidándose. Una decisión difícil que Timbre de Gloria justifica ampliamente en ambas versiones.

El fragmento que sigue así lo demuestra. Y, a pesar de su extensión, es interesante reproducirlo para entender cuanto se ha dicho hasta el momento del cuento:

Distante muchas jornadas del castillo de Timbre de Gloria estaba el de la hermosa; a él se encaminaron padre e hijo, cargados de riquísimos presentes, con gran séquito de escuderos y servidumbre. No bien hizo la petición el caballero cuando le fue concedida; y al avistarse los prometidos, ambos a dos estuvieron a punto de desmayarse: tan hermosos y seductores se hallaron uno a otro, de tal modo traspasados por puntas de amor. Concertaronsé las bodas con el plazo perentorio de los preparativos, y, después de tres días de espléndidos festejos, partieron los peticionarios.

Tamaño acontecimiento trascendió hasta los reinos limítrofes: apenas si cabría en el mundo pareja más hermosa, más ilustre, y novios el uno para el otro más apropiados. Timbre de Gloria estaba como loco: aún a las fieras del monte, hasta a los mismos muros del castillo quería comunicarles su ventura; enajenábase con la ausencia: eternidad se le volvía la rapidez vertiginosa con que se gestionaban los aprestos y diligencias del matrimonio.

Más que con los garzones de su clase, le ligaban vínculos de tierna amistad con su maestro predilecto, el licenciado Reinaldo, varón doctísimo y preclaro, en quien cifró el mancebo cuanta fe y seguridad cupo entre amigos. El tal se hallaba, últimamente, en la corte, y Timbre de Gloria acudió en su busca, para hacerle partícipe de cuanto le acontecía y 
esparcirse con él en deliciosas confidencias.

Nunca tal hiciera. Grande atención prestó el licenciado al desbordante relato del doncel; y luego, con aire y tono de quien posee un secreto por nadie sospechado, dejóse decir estas palabras:

-Hermosa como el sol es tu prometida, amigo mío. Rica-hembra más celebrada no conozco; pero...

-¿Pero qué, maestro?

-¡Pero!... -volvió a decir el licenciado.

Y a que se explicase no fueron parte ni el ruego, ni las promesas, ni las lágrimas de su discípulo. Separóse de Reinaldo con el corazón emponzoñado. Ese | pero que nada definía, que nada concretaba, tuvo para él, en la boca autorizada de su maestro y amigo, la sugestión terrible de lo desconocido.

¿Qué sería? ¿Qué no sería? ¿Un alerta, acaso? ¿Un pronóstico? ¿Cuántas y cuáles consecuencias tendría eso en su destino? ¡Imposible adivinarlo! Mas, fuese esto, aquello o lo de más allá, no le cabía duda que era algo grave tal vez vergonzoso, que, en su inexperiencia de niño, no le era dado ni sospechar siquiera.

Sólo así se explicaba la obstinación de su maestro en aclarar el asunto; de otra suerte no concebía aquel | pero en boca por la que hablaban la prudencia y la sabiduría.

El tono que emplea Carrasquilla en esta narración emula al de las narraciones del Siglo de Oro utilizando, para ello, un lenguaje prolífico en cultismos y arcaísmos, grandilocuente, con profusión de adjetivos, exceso de enumeraciones y alterando el orden lógico de las palabras ${ }^{3}$.

Un esfuerzo con el que el novelista colombiano ofrece a su texto un aire épico similar a los textos contenidos en los libros de caballería de los siglos XVI y XVII. Asimilando, ya desde el nombre, las andanzas de Timbre de Gloria a las de los caballeros andantes de la talla de Amadís de Gaula, Belianís de Grecia o Florando de Inglaterra; aunque ofreciendo sus peripecias desde la crítica y el distanciamiento que ofrecen los siglos y una cultura distinta a la europea.

En el análisis del original de Carrasquilla hay que destacar, también, que los personajes, al igual que ocurría en las novelas de caballería, son planos,

\footnotetext{
${ }^{3}$ Baste un fragmento para comprobarlo: "Señores y vasallos, amigos y extraños competían en cariño al vástago precioso que trajo a la comarca tantas bendiciones. Timbre de Gloria confirmaba día por día el nombre que le dieron; en su persona pareció concentrarse el lustre y la grandeza de sus antepasados. El castillo, enantes tedioso y solitario, convirtió lo el infante en animada corte de placeres y discreteos", Tomás CARRASQUILLA, El ánima sola, asequible en: http://www.lopaisa.com/carrasq1.html Fecha de consulta: 21-01-2010.
} 
arquetípicos, se mueven por el devenir de la acción en la que se ven envueltos que parece arrastrarlos- y no evolucionan a medida que se suceden los acontecimientos.

Similar a la tradición caballeresca, el texto recoge temas propios de este género como el amor cortesano y la violencia glorificada que se muestra como camino para alcanzar la perfección. Olvidando, de forma intencionada, otros ingredientes del género como: el honor mancillado, la búsqueda de aventura, el ideal cristiano o las andanzas en post de la virtud, que nada aportarían al caso tratado.

Pues lo que interesa a Carrasquilla es la fragilidad con la que los héroes se desmoronan ante el menor imprevisto; en este caso, algo tan sencillo y cotidiano como una duda.

Así, cuando a Timbre de Gloria se le plantea la posibilidad de que sus decisiones no sean acertadas, en cuanto no son aplaudidas por quienes le rodean, el gigante se desvanece convirtiéndose en un títere sin voluntad.

Un punto de vista que coincide con los postulados de Buenaventura y su teatro de antihéroes.

Y un hecho que, posiblemente, despertó el interés del dramaturgo por el original novelado y le incitó a dramatizar la historia.

\section{Dramatización}

Enrique Buenaventura toma el testigo de Carrasquilla y elige la historia de Timbre de Gloria como punto de partida para crear una mojiganga.

Con ello obtiene una pieza que bien podría haber formado parte del reparto de una de las compañías de la legua del siglo XVII, por su formato, sus personajes, su ritmo y su planteamiento escénico (más cercano a un cuaderno de dirección que a un texto dramático)

La versión del dramaturgo cuenta con tres actos compuestos por 9, 2 y 5 cuadros respectivamente, que sigue las directrices del original en el desarrollo de la historia casi en su totalidad. Pues Buenaventura añade un nuevo capítulo titulado Armarlo Caballero con el que fortalece el elemento medieval de la propuesta que cuenta, desde ese momento, incluso con la participación de un Rey, que en el texto de Tomás Carrasquilla aparece sólo como una referencia cuando se narran los honores y se enumeran las personalidades que celebraron el nacimiento del protagonista ${ }^{4}$.

\footnotetext{
${ }^{4}$ Durante su parlamento, el Rey, que está armando caballero a Timbre de Gloria, se inventa la orden de los Timbres de Gloria, a quienes adjudica una finalidad: (...) despertar la cristiandad entera para que marche victoriosa a la conquista de Jerusalén y de las tierras nuevas donde Satán tiene su reino de sombras malignas” BUENAVENTURA, op. cit., 358.
} 
Del original, a Buenaventura le interesa la historia y el tono. Y, sobre ellos construye una comedia con nuevos personajes. Estas incorporaciones al elenco original aproximan la historia inicial al público y son las herramientas que emplea el dramaturgo para fortalecer alguno de los elementos dramáticos de su propuesta.

Así, la trama dramática la desarrollan 19 personajes frente a los 7 personajes del cuento (tratando como un solo personaje al grupo conformado por las 13 hijas que tiene el castellano antes de que nazca el varón)

Los 19 personajes no participan por igual en el desarrollo del conflicto. De ahí que sea necesario organizarlos en tres grupos. Por un lado, se encuentran los protagonistas de la historia (Timbre de Gloria, el Castellano, Reinaldo, Flor de Lis, las mujeres del Castellano, el Arcángel, etc.) Personajes a los que les suceden las cosas, que ponen nombre propio a lo que va aconteciendo sobre la escena, que sufre sus consecuencias y sus premios. De otro, se encuentran los personajes narradores (principalmente, La Muerte y La Buscona aunque se podría considerar también el personaje del Cura) que explican la historia desde dos puntos de vista diferentes, que opinan sobre todo cuanto acontece y que, incluso, interactúan con los personajes de la trama principal. Esta nueva herramienta multiplica las posibilidades de recepción de la historia, fortalece el ritmo de los acontecimientos, soluciona saltos temporales y cambios de espacio escénico.

Con este reparto desarrolla una trama que localiza, sólo vagamente, en el espacio y en el tiempo. Así afirma que los hechos sucedieron "En el centro de la cristiandad" (se supone, por tanto, que en España) y en el tiempo de la barbarie, es decir, durante las Cruzadas.

Con este elenco, Enrique Buenaventura se permite desarrollar algunos puntos que aparecen menos desarrollados en el cuento original. Verbaliza los deseos de algunos personajes, lo que le sirve para contar más datos de los personajes y justificar muchas de las cosas que le van a suceder, por inverosímiles que puedan parecer ante los ojos de los espectadores y las espectadoras $^{6}$. Introduce la poesía como si se tratara de una manera natural de expresión de los personajes. En especial el castellano y el coro, lo que fortalece

\footnotetext{
${ }^{5}$ Con el nombre genérico de cruzadas se hace referencia a las campañas militares sostenidas con motivos religiosos (recuperar Tierra Santa para los peregrinos) que llevaron a una buen parte de Europa al enfrentamiento, sobre todo, con los musulmanes. En realidad, eran enfrentamientos motivados por enfrentamiento comerciales y expansionistas de la nobleza feudal europea y por el afán de los papas por hacerse con el control de las iglesias de Oriente.

${ }^{6}$ Un ejemplo es el que protagoniza el personaje del castellano casi al comienzo del texto, cuando expone sus deseos de contar con descendencia varón: Dice "iUn gigante! Necesito un gigante que acabe con todos mis enemigos, que preñe a todas las mujeres del reino y tenga miles de hijos varones para defender y propagar la estirpe”, BUENAVENTURA, op. cit., 349-350.
} 
el tono de teatro de la legua ${ }^{7}$. Emplea el recurso del CORO para solucionar el paso del tiempo y poder presentar a Timbre de Gloria en su adultez ${ }^{8}$.

Hay que señalar también que son pocas las referencias escenográficas que hay en la obra. Y sólo en un par de ocasiones encontramos orientaciones en este sentido. Indicaciones que están cargadas de efecto como, por ejemplo, cuando indica, hacia el final de la propuesta, que, ante la mirada de los espectadores y las espectadoras, el castillo se convierte en ruinas. Una acción sobre la que podría escribirse todo un libro dada su simbología y el marco histórico al que alude.

Otra novedad del texto dramático es la aparición de voces colombianas, lo que no ocurre en el original de Carrasquilla. Elementos con los que consigue mayor cercanía entre los personajes y los espectadores y espectadoras.

Para potenciar la acción en el discurso, Buenaventura opta, casi de forma exclusiva, por el diálogo. Así, son pocas las acotaciones que encontramos en el texto y, casi siempre, se refieren a elementos orientados a la puesta en escena, fundamentalmente al elemento sonoro de la misma. Por ejemplo: "Alarido gemebundo y escalofriante de la parturienta"; "Gritos de la parturienta, carreras de criadas y criados con aguamaniles, paños y vasijas" "Escándalo de los ahorcados y gritos de la parturienta", "Un oh de admiración de todos los invitados", "Otro oh, más prolongado que el anterior, recorre la multitud", "El CORO DE INVITADOS se divierte con el niño".

\section{Dos niveles: la historia y la representación}

La estructura dramática de la propuesta teatral se basa, como ya se ha adelantado anteriormente, en la fuerza y la función que cumplen los distintos personajes escogidos por Buenaventura.

Así, en lo que respecta a los personajes La Muerte y La Buscona hay que señalar su relación directa con la narración de los hechos al tiempo que establece un contacto directo con el público, rompiendo con ello la cuarta pared y, por tanto, rompiendo cualquier intento de realismo que pueda entenderse en la historia.

Este dúo (Muerte- Buscona) introduce un elemento didáctico que facilita la comprensión de cuanto sucede en el escenario por parte de los espectadores, conciente el autor de que el público que iba a recibir la propuesta no siempre tiene los datos precisos para ubicar en el tiempo y en el espacio cuantos acontecimientos se suceden ante sus ojos.

\footnotetext{
${ }^{7}$ Ibidem, 354. Lo recita el Castellano cuando va a anunciar, públicamente, el nombre que le va a poner a su hijo.

${ }_{8}^{8}$ Dice el coro: "Ya camina a cuatro pies, / ya recorre todo el suelo, / ya corre sin un traspiés, / ya casi levanta el vuelo", BUENAVENTURA, op. cit., 355.

${ }^{9}$ Ibidem, 352, 353, 354 y 355.
} 
La relación entre ellos (Muerte- Buscona) es conflictiva porque cada uno cuenta la historia de una manera distinta, lo que ocasiona escenas cómicas entre ambos que aligeran la posible gravedad de la trama. Así, por ejemplo, el personaje de La Muerte echa de escena a La Buscona alegando a su favor que "Éste es un relato piadoso, hecho para convertir a los infieles, para arrancarlos de las garras del demonio y en un relato así no caben las perdidas como vos ${ }^{210}$.

Otras incorporaciones a la propuesta original, no contempladas como personajes en el texto de Carrasquilla son: las dos primeras mujeres del padre del protagonista, al que mantiene con el nombre de "Caballero". Un milagro que muda en escena grotesca, pues para hacerlo, a la muerte le ayuda el Arcángel San Miguel al tiempo que introduce otra novedad: la brujería. Pues las dos esposas asesinadas por el Caballero, al resucitar, se vengan de éste lanzando un maleficio sobre el hijo varón que tanto celebra el castellano -que no está en el original como bien indica la propia Muerte, que las vuelve a asesinar para que no interfieran en su explicación de los acontecimientos:

\section{ESPOSA PRIMERA}

¡Maldito siás, engendro del demonio! ¡Me ahogaste con la almohada porque no te di un hijo varón!

ESPOSA SEGUNDA

¡Monstruo sin entrañas! Me degollaste con el puñal porque no te di un hijo varón...

\section{LAS DOS (en coro)}

Tu único hijo morirá sin trascendencia. ${ }^{11}$

También es novedosa la incorporación de una especie de fantasma que se denomina con el nombre de "La Aparición", un personaje que se encuentra a medio camino entre el Arcángel San Miguel y Timbre de Gloria, que se aparece ante Reinaldo para torturarle.

Y sobre el que la Buscona, en su función narradora, afirma que es el fantasma de Timbre de Gloria quien, por haberse suicidado, se aparece de tal guisa.

Con este nuevo personaje se introduce, además, el tema de la venganza. Haciéndolo, además, al más puro estilo Hamlet, pues el propio Timbre de Gloria se aparecerá ante Flor de Lis para pedirle que vengue su muerte ante

\footnotetext{
${ }_{10}$ Ibidem, 345. A ello añade, la muerte, que su narración es por encargo y que va a contar la historia " (...) como me han pedido los santos del cielo y los devotos misioneros de la tierra que lo cuente" (p. 346) Y que esta misión recae sobre ella porque "Soy la imparcialidad absoluta y la verdad en pepa" (p. 345) Una afirmación a la que la Buscona responde en más de una ocasión, afirmando: "Una Historia no es nunca de una sola manera" (p. 352).

${ }^{11}$ Ibidem, 347 y 348.
} 
Reinaldo, contándole, además, el comentario que sembró en él la duda ante su inminente enlace y le condujo hasta la muerte prematura:

\section{APARICIÓN}

Su lengua tuvo la culpa de todo. Ha ingresado a un convento de monjes trapenses... esos que no dicen jamás ni media palabra. Denunciadlo, Flor de Lis, que pierda su lengua ${ }^{12}$.

El tema de la magia se amplía otra vez en la versión teatral para tratar, además, el tema de la superchería popular. El ejemplo más claro sucede cuando la Buscona le da un brebaje a la tercera esposa del castellano para conseguir que quede embarazada de hijo varón y le indica la forma y el momento en que debe tomarse. Pero también cuando el mismo personaje amenaza al Castellano quien pone en duda la eficacia de sus artes de hechicería consiguiendo que éste se muestre sumiso ante lo sobrenatural. Un elemento que descubre una faceta cobarde en el personaje que no tenía en el original de Carrasquilla. Para comprobarlo basta la lectura de los dos siguientes ejemplos. El primero correspondiente al cuento; el segundo, a la obra de teatro:

Mándale el padre ponerse de rodillas y, en cuanto lo hace, córtale a tajos la cabellera de arcángel; júntala en manojo, y cual si fuera rayo de su cólera, lo lanza hasta el corral. Cógele por el cuello y lo levanta, tómale la espada, pártela en dos contra la rodilla y arroja los pedazos a un foso; despójalo de la espuela y las insignias, y, a dos manos, frenético, insano, le arranca, le desgarra, le hace añicos recamos, sedas y holandas. En viéndole desnudo, le echa encima las repugnantes pieles; cíñele luego los hierros remachándoselos él mismo con su propia mano. Apártase unos pasos, no bien termina; brama de ira y, entre acecidos y temblores, le dispara estas palabras:

¡Maldito sea el día en que te engendré! ¡Malditas las entrañas que te concibieron! ¡Aparta de mi vista, hijo desnaturalizado! ¡Véte a acabar tu vida, enterrado a pan y agua, en el sótano más hondo del castillo! ¡Púdrase tu cuerpo, hierva de gusanos antes de morirte, abísmese tu alma en los infiernos y caiga sobre tí la maldición de tu padre!

Repitió el eco las palabras, obscurecióse el cielo, corrió el espanto en la comarca; y Timbre de Gloria, escoltado por sus propios escuderos, marchó a la condena.

\section{LA BUSCONA}

¡Alto, su señoría! ¿Si me toca convierto a ese varón que está a las puertas del

12 Ibidem, 375. 
vientre de su madre en una chorrera de hembras furiosas que lo perseguirán por el resto de sus días!

\section{CASTELLANO}

¡No, no, por favor! Creo en tus poderes, en tus hechizos y en tus dotes sobrenaturales... ¡Pedíme lo que querás! ${ }^{13}$

A excepción de algunos elementos mínimos como éste que se acaba de comentar, a los personajes de la historia original, Buenaventura les potencia los elementos más característicos de su carácter. Así, el dramaturgo agudiza la crueldad del castellano llegando a extremos impensables para un cristiano. Por ejemplo, amenazando al mismísimo Arcángel San Miguel con matarle si no tiene un hijo varón. Refuerza también su machismo poniendo en su boca frases como: "¡La mujer es la perdición de los hombres! ¡Por ella Adán se comió la manzana! ${ }^{14}$ E incluso, llegando a afirmar que él mismo acabará con todas las mujeres.

Siguiendo con el vínculo entre personajes y trama hay que señalar también que Buenaventura desarrolla la relación que une a Timbre de Gloria con su maestro Reinaldo ofreciendo pasajes y datos nuevos, no contemplados por el cuento de Carrasquilla.

Parlamentos en los que conocemos el carácter austero y ambiguo de Reinaldo al tiempo que descubrimos a un joven Timbre de Gloria en plena efervescencia hormonal adolescente.

Precisamente es estos pasajes donde descubrimos que Reinaldo es el verdadero protagonista de la acción de la historia, al tiempo que se justifica la dependencia que Timbre de Gloria tiene con su maestro.

Así, para Buenaventura, Reinaldo propicia el primer encuentro sexual de Timbre de Gloria con el sexo femenino (en especial con una criada) acción que incluye como un ejercicio más de la formación del joven pupilo ${ }^{15}$. Le incita a que no se entregue a una sola mujer (Dice el maestro: "Una mujer es un ancla. Vos sois un navío sin amarras que llegará muy lejos" ${ }^{\text {"16 }}$. Le introduce en la degustación del alcohol, en este caso vino ("Hay que aprender a tomarlo con mesura. Es

\footnotetext{
13 Ibidem, 351.

14 Ibidem, 349.

${ }_{15} \mathrm{La}$ Buscona es el personaje encargado de narrar este interés del joven por el sexo que no se encuentra en el original de Carrasquilla, quien lo presenta como un joven más interesado en la batalla que en los placeres de la carne. Dice La Buscona: "Habíase desatado el heredero! ¡No quedaba en el castillo doncella, casada o viuda que no fuese pasada por sus armas! ¡Los padres de las doncellas se hacían de la oreja mocha, los desesperados maridos se rompían los cuernos contra los muros del castillo y dicen las malas lenguas que hasta los esposos muertos salían de sus tumbas para ver el jolgorio de sus viudas honorables", BUENAVENTURA, op. cit.,357-358.

16 Ibidem, 357.
} 
indispensable en la vida mundana y aún diría yo que en la vida recogida y contemplativa. Es amigo y enemigo. Hay que tratarlo con prudencia"17

Pero, quizá la aportación más importante de Buenaventura es que introduce respecto a Reinaldo es su apego por la religión y la forma en que quiere hacer de

ella Timbre de Gloria. Una opción que descubre las ambiciones de este hombre, las razones por las que se niega al matrimonio de su alumno con Flor de Lis y la razón de que siembre en él la duda.

Así hay un bellísimo e interesante parlamento en el que Reinaldo, desesperado por los sentimientos de Timbre de Gloria, le propone que se dedique a la vida eclesiástica como alternativa a una vida doméstica:

REINALDO.

"Vuestro padre ha cortado, en flor, las esperanzas que yo había puesto en voz, señor.

(...)

Os encerrarán en este antro de campesinos analfabetos con esa mujer. Si es honesta y recatada os llenará de hijos y si es perversa, como casi todas las mujeres, os llevará a la muerte para evitar el deshonor y arruinará la estirpe" $(\ldots)$

"La estirpe es importante, pero más importante es la cristiandad. El reino es importante, pero más importante es el universo"18

Acto seguido le invita a marcharse a otra ciudad, de la que él es originario, para dedicarse a la vida religiosa y donde, gracias al poder de su padre, será, primero, obispo y luego cardenal, materializando la razón por la que él accedió a ser su maestro. Y, de nuevo, aparece la magia como elemento determinante:

\section{REINALDO}

Se me apareció la Virgen. Sí, sí, la santísima Virgen, la única mujer que merece nuestra devoción y nuestra confianza. Se me apareció en la caballeriza del castillo. Ella me dijo: Un día os llamarán de lejanas tierras para educar al único heredero de una gran estirpe $y$, sin daros cuenta, formaréis un papa $^{19}$

Este gusto de Reinaldo por la milagrería lo desarrolla Buenaventura a hasta degradar al personaje, haciendo que afloren sus ambiciones personales y el plan que ha estado forjando teniendo la educación del joven heredero a su cargo. Así, Reinaldo deja de aparecer ante el espectador como la persona sabia que

${ }^{17}$ Idem.

18 BUENAVENTURA, op. cit.,360.

${ }^{19} \mathrm{El}$ parlamento es mucho más extenso. Ibidem, 361-362. 
aparentaba para convertirse en una especie de brujo que lanza alferecías durante el primer encuentro entre Timbre de Gloria y Flor de Lis para evitar que se enamoren:

\section{REINALDO}

Virgen de la caballeriza, haced que sea trastorno pasajero y que cuando reviva la encuentre tan fea como una bruja. Torcedle la nariz y la boca, sacadle algunos dientes, aflojadle las tetas y descolgadle la cadera, que quede pro lo menos coja y tuerta ${ }^{20}$

Para el dramaturgo, Timbre de Gloria es poco más que un niño consentido, mimado, al que sólo le preocupa su bienestar y que mueve su voluntad en función de sus impulsos. Así, de obedecer las instrucciones de Reinaldo (ya que responden a sus necesidades) pasa a ser esclavo de los sentimientos que despierta en él Flor de Lis. Y así lo reconoce él mismo:

\section{TIMBRE DE GLORIA}

Sólo en Flor de Lis. Es curioso, he olvidado todo lo demás. No me pidáis que piense en mí, que piense en mi destino, en la estirpe, en la cristiandad, en el reino o en el universo ${ }^{21}$.

Finalmente, es necesaria hacer una referencia al personaje de Flor de Lis, que Buenaventura refuerza otorgándole carácter y convirtiéndola en elemento activo de la acción y no sujeto pasivo que recibe las consecuencias de las decisiones que toman los demás en torno a ella. Lo que fortalece la línea de acción y mantiene el conflicto dramático, a pesar de la desaparición de Timbre de Gloria.

Así, aunque sabe que está sometida a la voluntad masculina socialmente establecida, reclama para ella el daño que hace el heredero al decidir que no se casa con ella: "No está ofendiendo a mi padre. Me está ofendiendo a mí y si tiene alguna razón para ofenderme que la diga", señala en su defensa. Y, posteriormente continúa con una amenaza directamente dirigida a Timbre de Gloria, cuando todavía vive:

\section{FLOR DE LIS}

Juro, por mi juventud y mi belleza, que arrastraré su nombre por el suelo y si quiere deshonra y deshonor los va a tener a manos llenas ${ }^{22}$.

\footnotetext{
${ }^{20}$ Ibidem., 365.

${ }^{21}$ Ibidem, 368.

22 Ibidem, 371.
} 


\section{Conclusiones}

En cualquier caso, la referencia a la historia bíblica, que se apunta como originaria de esta alma en pena, se revisa en ambos casos y, en ninguno de ellos, aparece un elemento de culpa que origine la penitencia de esta mujer. Lo hace como una condena que le llega sobrevenida por las condiciones sociales que repudian a una mujer que ha sido rechazada justo antes de casarse. De ahí que el Enrique Buenaventura subraye el machismo de sus personajes en repetidas ocasiones.

Un contexto en el que ambos, dramaturgo y novelista, articulan una historia para que esta mujer en pena consiga limpiar su honor, provocando que la persona culpable se descubra ante ella, le perdone, pero cobre por ello una tasa: su lengua.

Esta lengua aparece como un guiño cómico más de la propuesta teatral al tiempo que hereda y homenajea el gusto por lo sobrenatural de la literatura romántica del siglo XIX, donde era frecuente encontrar partes del cuerpo que se mueven de forma independiente e incluso, atacaban al resto de cuerpo humano. Así pues, esta lengua aparece como un personaje con su momento y su correspondiente protagonismo, al hacer Buenaventura que palpite y se retuerza ante la mirada atenta del público en un escenario vacío de otra actividad.

En este texto, pues, Buenaventura revisa y actualiza la cultura popular de su Colombia natal, los mitos, ridiculiza las posturas más extremas y apuesta por el libre albedrío, por la posibilidad de cambio que tenemos las personas ante el mandato del destino y el referente femenino.

Toda una apuesta por la libertad en mayúsculas y por los derechos de las mujeres ${ }^{23}$.

23 Lugares de interés en la web sobre Enrique Buenaventura: Centro Virtual Isaacs http://dintev.univalle.edu.co/cvisaacs/enrique_buenaventura/index.htm y Sitio oficial de Enrique Buenaventura: http://www.enriquebuenaventura.org/ 